\title{
Anatomia de Anacardium spruceanum Bth, Ex Engl. (Anacardiaceae da Amazônia).
}

José ELIAS DE PAULA*

José LUIZ DE HAMBURgo ALVES ${ }^{* *}$

\begin{abstract}
SINOPSE
Neste trabalho é estudada a anatomia do caule, lâmina foliar, pecíolo, madeira, fruto e semente de Anacardium spruceanum. Foram consideradas as estruturas primárias indiferenciada (meristema primário), primária diferenciada e secundária. São investigadas a origem dos canais secretores e a natureza das substâncias por eles secretadas.
\end{abstract}

\section{INTRODUÇÃO}

Considerando que o gênero Anacardium componente de nossa flora, apresenta grande importância do ponto de vista econômico e medicinal, e que, sob o aspecto anatômico, tem sido pouco estudado, procedemos a investiga. çâo com o objetivo de esclarecer sua anatomia $\in$ levantar questões correlatas com a Taxonomia e Ecologia, com vista à aplicação no campo econômico, pela industrialização do pseudo-fruto (hipocarpo), do fruto propriamente dito, inclusive a semente, de algumas espécies do referido gênero, notadamente Anacardium occidentale L. Igualmente, ressalte-se seu valor medicinal. em face das diversas aplicações em que tem sido utilizado. Aguiar et alii (1958), referem-se à ação da injeçāo do decocto de Anacardium occidentale, produzindo uma redução acentuada na glicemia em ratos normais e adrenolecte. mizados, via intravenosa, e intraperitonial em ratos submetidos a insulina (Aguiar \& Fainzilber. 1958). Os referidos autores frizam que Arduino \& Soares (1951) observaram a rápida absorçäo do fator hipoglicemiante pelo tubo gastroentérico, com conseqüência hipoglicémica sem exteriorização clínica correspondente, em diabetes mellitus. No caso de Anacardium spruceanum, além das aplicações industriais já mencionadas, sua madeira é utilizada, especificamente, como matéria prima para produção de celulose para papel (comunicação pessoal de Roberto de F. Lobato \& Antônio Corrêa Azevêdo, químicos industriais da Usina Piloto de $\mathrm{Pa}$ pel e Celulose, pertencente ao Instituto Nacional de Pesquisas da Amazônia).

Constitui, também, parte integrante do trabalho cujo sumário foi publicado no Resumo dos trabalhos da XXI Reunião Anual da Sociedade Brasileira para o progresso da Ciência, 1970.

\section{IMATERIAL E MÉTODOS}

Utilizamos neste trabalho: caule, folha de sol, da parte mais alta da copa da árvore, madeira, fruto e semente, fresco e fixado, de espécimes adultos, sendo coletado de três indivíduos, dois dos quais registramos nos herbários do Instituto Nacional de Pesquisas da Amazònia (INPA) e Universidade de Brasília (UB); com os seguintes dados:

a) Procedência: Estado do Amazonas, Manaus, Reserva Florestal Ducke, mata primária da terra firme; coletor: J. Elias de Paula 466, em 11-3-1969; número de herbário : UB 40459; determinador: J. Elias de Paula.

b) Procedência: Manaus, Reserva Flo. restal Ducke; coletor: Byron, INPA 28282.

Usamos para fixação de material, FAA a FPA. Os cortes histológicos foram executados à mão livre, com gilete e micrótomo rotativo de Spencer, segundo a técnica da inclusão de material em parafina. Com relação aos cortes para estudo histológico da madeira, foram pro-

(*) - Universidade de Brasília

(**) - Universidade Federal de Pernambuco. 
cessados através do micrótomo Jung para madeira. Quanto a epiderme foliar, realizamos sua dissociação, empregando a mistura de Jeffrey (Johansen, 1940). Os compostos fenólicos foram identificados por meio do teste metacromático (O'Brien et alii, 1964). Para a identificação das substâncias proteicas, utilizamos Fucsina ácida, e também a reação Xantoproteica (Jansen, 1962). Os grãos de amilo foram identificados, por apresentarem coloração roxoazulado na presença do Lugol, e também sob luz polarizada, de cujo efeito resulta uma zona escura: denominada "Cruz de Malta". A presença de compostos lipídicos foi constatada pela coloração laranja-avermelhado, mediante a solução alcoólica de Sudan III.

As fotomicrografias foram obtidas através do Fotomicroscópio Zeiss. Adotamos a terminologia de Milanez \& Miranda Bastos, 1960; Kribs, 1935; Esau, 1959; Metcalfe \& Chalk, 1957 e a recomendada pela Primeira Reuniăo de Anatomistas de Madeira, 1936, em Rodriguésia. 1937.

\section{Resultados}

\section{A - CAULE}

a) Estrutura primária indiferenciada (meristema primário). Na estrutura primária indiferenciada observa-se, na direção periferia-centro, as seguintes camadas : protoderme - células protodérmicas apresentam subglobosas a subretangular, vista em secção transversal, em geral taníferas, ocorrendo pelos glandulares, uni e pluricelulares; sobre a protoderme já se observa uma cutícula bastante fina. Parênquima fundamental cortical - é constituído de células, geralmente, amplas e de formas variadas, ricas em proplástídios; entre elas, há células taniferas. Procâmbio - é representado por cordões dispostos simetricamente, em círculo delimitando a medula; suas células são menores que as células corticais e medulares, com citoplasma muito denso e núcleo grande, em relação ao tamanho da célula; nesta fase de diferenciação jả se notam esboços de alguns canais secretores (foto 1). Parênquima fundamental medular - apresenta, também estrutura idêntica a descrita no parênquima cortical. b) Estrutura primária diferenciada. Epiderme glabra; em secção transversal as célulàs epidérmicas são, de modo geral, alongadas, com maior diâmetro na direção anticlinal, resultante de divisōes anticlinais de células protodérmicas, com paredes pectocelulósicas; entre essas células ocorrem algumas com polifenois: cutícula fina e uniforme. (foto 2).

Parênquima cortical. Constituído de células anisodimensionais, em secção transversal, com paredes finas, pectocelulósicas; é realmente marcante a presença de células com polifenois, sendo que a maior concentração dessas células está na porção mais externa desse parênquima, de modo a formar uma verdadeira bainha; ocorrem canais secretores na porção periférica do parênquima cortical; são freqüentes idioblastos contendo drusas de oxalato de cálcio.

Sistema vascular. O caule de Anacardium spruceanum, pela distribuição dos feixes vasculares, apresenta estrutura sifonostélica ectoflóica; os feixes vasculares sảo colaterais, aparecem de 6 a 11 grupos, dependendo da espessura do caule; o procâmbio é contínuo; e evidente a formaçăo de canais, e células taníferas, na região do floema (foto 3 ), cujo diâmetro desses canais é maior que o diâmetro dos canais de outras regiōes; na estrutura primária plenamente diferenciada, uma bainha de esclerênquima começa a se constituir em torno desses canais.

Parênquima medular. Consta de células de forma e diâmetro variados, com paredes finas, pectocelulósicas; gräos de amilo escassos; pequenos, simples, raramente compostos de 2, as vezes de 3 , com hilo circular, central; células taníferas são frequentes nesse parênquima. Canais, também, estão presentes e situam-se na porção externa do parênquima medular, de diâmetro relativamente grande em comparação com os da porção periférica do córtex, e freqüentemente aparecem juntos dos feixes vasculares (um para cada feixe).

c) Estrutura secundária. Analizando cortes transversais e tangenciais de caule, observamos que o felogênio é de origem subepidérmica; produz pouco súber e muito menos, ainda, feloderma. No felema, além das células suberosas, notam-se as esclerosadas, com pa- 

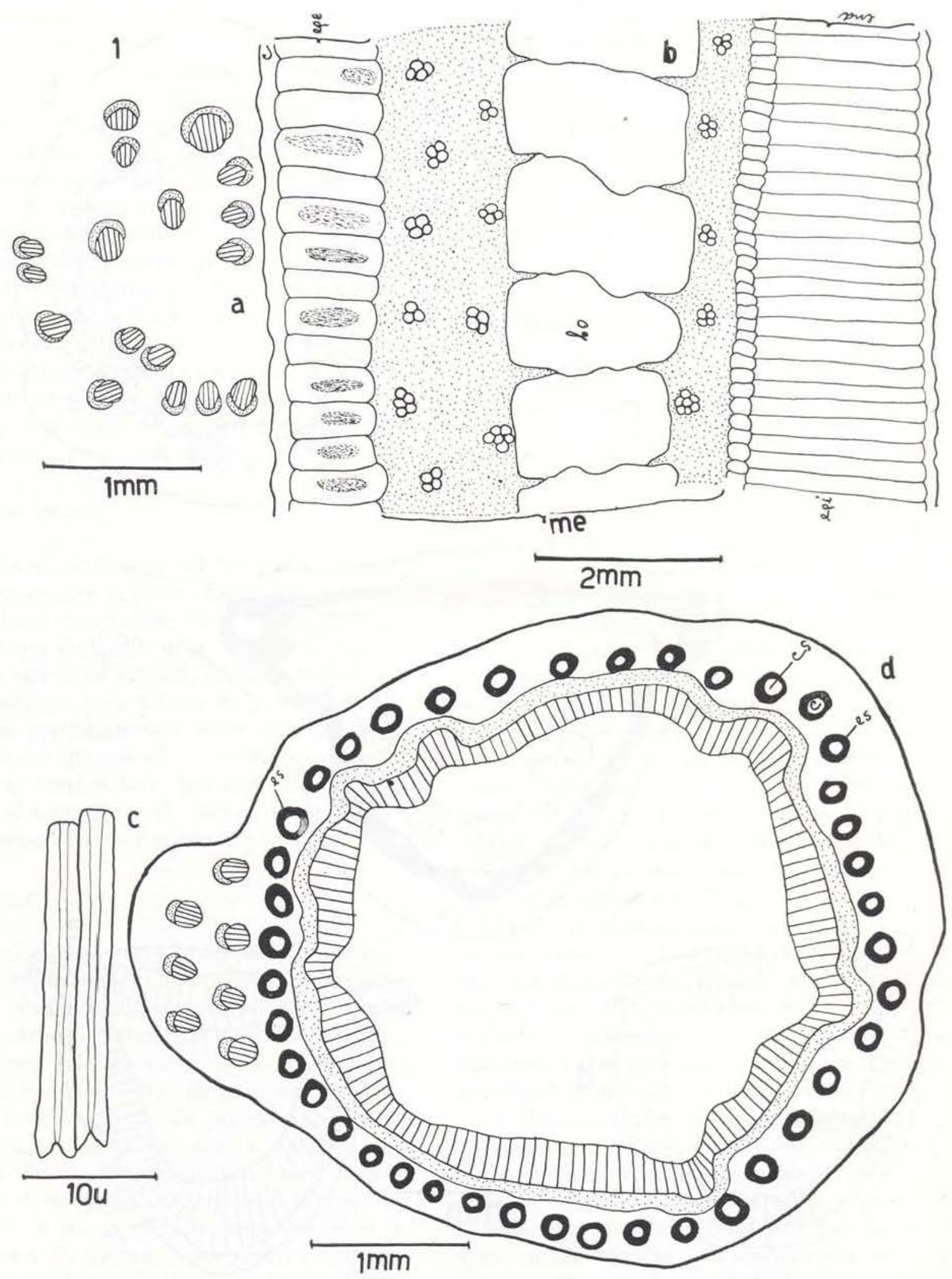

Fig. 1: a) Sistema vascular da extremidade proximal do pecíolo; b) Fruto: desenho esquemático do pericarpo ( $c$, cutícula; epe, epiderme externa; me, mesocarpo; end, endocarpo; epi, epiderme interna; bo, bolsas); c) células dissociadas da epiderme interna do pericarpo; d) caule : corte transversal ao nível do nó foliar (cs, canal secretor; es, esclerênquima). 


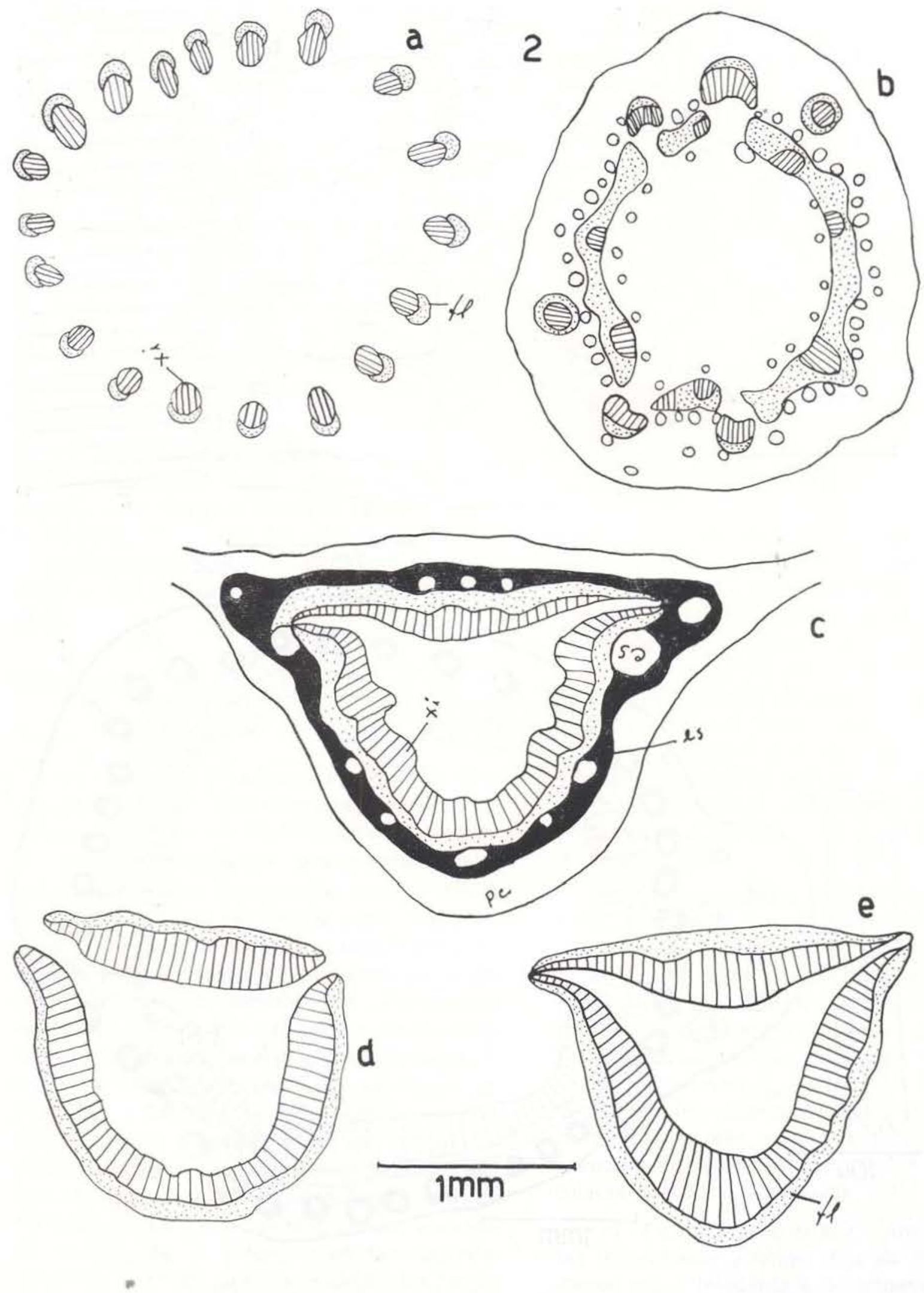

Fig. 2: a) sistema vascular da extremidade proximal do pecíolo, um pouco afastado do ponto de inserçâo; b) caule, estrutura primária, mostrando canais secretores na região do floema, e rastros foliares; c) sistema fibravascular da nervura central ( $x i$, xilema; es, esclerênquima; $c s$, canais secretores; $p c$, parênquima cortical); d) sistema vascular da porção média do pecíolo; e) sistema vascular da extremidade distal do pecíolo. 
redes lignificadas. Os canais secretores se formam também na estrutura secundária; aqui, em geral, eles são envolvidos por esclerênquima (foto 6). Tanto o parênquima cortical como o medular são ricos em células contendo polifenois. No floema, além das células radiais, outras ocorrem que contêm polifenois. A zona cambial é constituida de 3 a 5 camadas de células, incluindo as iniciais fusiformes e iniciais radiais do câmbio. A maior massa do lenho secundário é representada por fibras de paredes finas, lignificadas; os vasos lenhosos são abundantes, simples ou múltiplos, distribuídos isoladamente, ou em série; os raios são 1-2 seriados, e seus elementos são, em geral ricos em polifenois; o parênquima axial é escasso, nele ocorrem bolsas pequenas, resiníferas.

\section{B - RASTRO FOLIAR}

Analisando cortes do nó foliar, obtidos em série da base para o ápice, constatamos que o rastro foliar é constituído de 6 feixes flóioxílicos, cada um deixando uma lacuna; a medida que estes feixes se afastam do cilindro central, vão convergindo para a base do pecíolo, aí, alguns deles dividem-se em outros feixes, que juntos com os demais vão constituir o sistema vascular da extremidade proximal do pecíolo (fig. 1-a e d e fig. 2-a e b). No nó foliar, os canais são envolvidos por esclerênquima (fig. 1-d).

\section{C - PECíoLo}

Epiderme glabra. Quanto ao parênquima fundamental observa-se, que a partir aproximadamente da porção média do comprimento do pecíolo, em direção distal, logo abaixo da epiderme há uma camada de células de paredes finas lignificadas. No parênquima cortical ocorrem muitas células de paredes finas, lignificadas. Em geral, os canais situados na região do floema são envolvidos, pela face externa, por elementos esclerenquimatosos. O colênquima é pouco característico em todo o comprimento do pecíolo, constituído em geral, de 2 a 3 camadas de células. O córtex é rico em células que contém polifenois. O sistema vascular, na porção proximal, junto à inserçâo no caule é constituído de vários cordões, dispostos isoladamente e desordenados (fig. 1-a).
A medida que se afastam do ponto de inserção. vão se organizando de modo a formar unia circunferência, embora ainda estejam isolados (fig. 2-a). Já da parte média (fig. 2-d) para a extremidade distal (fig. 2-e), os feixes vasculares vão se unindo e formando, inicialmente, um arco semi-fechado, de sorte que, na extremidade distal, este arco é completamente fechado, lembrando o aspecto de uma figura quase deltóide.

\section{D - LÂMINA FOLIAR}

A epiderme adaxial é quase glabra; células epidérmicas, vistas em secção transversal são de formas variadas; as mais típicas são as de forma subretangular, retangular, com maior diâmetro na direção anticlinal ou subglobosa, todas com paredes finas, pectocelulósicas. A cutícula é fina, um pouco ondulada e estriada. Em vista frontal, as células, de modo geral, apresentam contorno muito irregular, embora ao nivel das nervuras, apresentem-se, às vezes, em forma triangular. Nesta epiderme as estrias cuticulares são bem conspícuas. Esparsamente, ocorrem pelos glandulares. A epiderme abaxial apresenta células de forma subglobosa, vistas em secção transversal, em geral ricas em polifenois; cutícula fina; quase uniforme e estriada. Em vista frontal, apresenta também células de contornos irregulares, sendo que na região das nervuras elas são retangulares. Pelos glandulares são freqüentes, uni e pluricelulares, geralmente flabeliformes e semi-circulares (foto 7). Estômatos estão presentes sòmente na epiderme abaxial, ocorrem 157 estômatos por $\mathrm{mm}^{2}$, em média; são do tipo anomocítico (ranunculáceo); com diâmetro po'ar (paralelo a abertura) entre 26 e $29 \mu$, e diâmetro equatoria! (perpendicular ao anterior) cerca de $21 \mu$. Habitualmente, os paraestomatocitos contêm polifenois; em secção longitudinal, o lúmem dos estomatocitos, na porção mediana, é ligeiramente estreitado; visto em corte transversal, nota-se, nas paredes "internas" um espessamento muito reduzido. Mesofilo - a folha de Anacardium spruceanum é dorsiventral. 0 parênquima paliçádico é constituído de duas cainadas de células, em geral taníferas; em algumas regiões aparece apenas uma camada de células. Nesse parênquima aparecem esparsa- 
mente lacunas pequenas. $\mathrm{O}$ parênquima lacunoso apresenta espessura aproximadamente igual à espessura do paliçádico, sendo que em algumas regiões da folha o paliçádico se apresenta mais espesso; entretanto, na região próxima à nervura central, o parênquima lacunoso é mais espesso que o paliçádico. Observa-se que as lacunas desse parênquima são, via de regra, pequenas. Os elementos vasculares são envclvidos por uma bainha de esclerênquima. Nervura central - Imediatamente abaixo das epidermes abaxial e adaxial, há duas a três ca. madas de células taníferas. Canais secretores são formados na região do floema, e devido ao aumento em diâmetro, eles atingem também o parênquima cortical, e são dispostos, simètricamente, em torno do sistema vascular, de mano ra uniforme. A região do floema é rica em células contendo polifenóis. A região vascular cuja forma assemelha-se a uma figura deltóide, vista em secção transversal, é envolvida por uma bainha de esclerênquima, constituída de fibras e esclerócitos (fig. 2-c). Canais secretores estão ausentes da medula. $\mathrm{Na}$ epiderme abaxial de algumas nervuras estudadas, ocorrem criptas revestidas de células secretoras e no seu interior, há pelos também secretores. pouco típicos; essas formações secretoras são nectários extra-florais.

\section{E - FRUTO}

A epiderme é simples e representa o próprio epicarpo. cujas células são alongadas anticlinalmente, em geral com $44 \mu$ de altura, variando entre 42 e $48 \mu$; paredes finas pectocelulósicas; ricas em polifenois, notadamente, taníno, e também resina. Cutícula espessa. esparsamente ocorrem estômatos que, vistos em corte transversal apresentam uma câmara subestomática relativamente grande. (Foto $8 \mathrm{e}$ fig. 1-b).

Mesocarpo - Constitui a parte mais espessa do pericarpo (fig. 1-b, me, e foto 8 ); suas células são colenquimatosas, observadas em material tratado com hipoclorifo de sódio e meio aquoso. De modo geral essas células são ricas em éleo-resina e substâncias fenólicas (foto 8). Os feixes vasculares são anfiflóicos. Na porção mais ou menos central do mesocarpo ucorrem bolsas, separadas por um tecido cons- tituído de fibras lignificadas e por células com paredes pectocelulósicas (fig. 1b, bo). As paredes de separação das bolsas são revestidas de células secretoras, de semi-globosas a alongadas, isoladas ou agregadas, semelhantes a pelos pluricelulares (foto 13). A existência dessas células, sugere que são as responsáveis, em parte, pela grande quantidade de óleo-resina existente no fruto, tendo as bolsas com reservatório. A confirmação desse fato poderá ser atingida com estudos posteriores de frutos jovens, nas diversas fases de desenvolvimento. Em algumas regiões da porção central do mesocarpo o tecido é mais ou menos reticulado, constituindo cada malha, uma bolsa pequena.

Endocarpo (fig. 1-b end). Constituído de duas camadas de células : a camada interna é representada por células pequenas, em comparação com as células da camada "externa", cuja altura média é da ordem de $256 \mu$. Considerando a presença de cutícula, consignamos a referida camada como sendo a epiderme interna do pericarpo. As células da camada externa do endocarpo possuem paredes espessas, lignificadas, apenas em algumas partes da parede, enquanto que as células da camada possuem paredes finas, pectocelulósicas. Em virtude de o estudo ter sido procedido em fruto maduro cu quase maduro, a denominação das camadas do pericarpo foi dada com base no que pudemos observar e nos nossos conhecimentos sobre o assunto. Essa nomenclatura entretanto, só poderá ser confirmada, mediante estudos de frutos jovens.

\section{F - SEMENTE}

Em Anacardium spruceanum, à semelhança de Anacardium occidentale, a semente é comestível, exalbuminada; geralmente apresenta cerca de $2-2,3 \mathrm{~cm}$ de comprimento por 0,6 a $1 \mathrm{~cm}$ de diâmetro; envolvida por um tegumento de cor bege-claro, na face externa e castanhoclaro na face interna, com 208-246 $\mu$ de espessura, facilmente destacável. O tegumento consta de duas partes bem distintas : tegumento externo e interno, O primeiro mede 128-166 $\mu$ de espessura, constitui-se de várias camadas de células grandes, de contorno muito irregular, com paredes espessas, pectocelulósicas, e contém pouco gräos de amilo; as células 


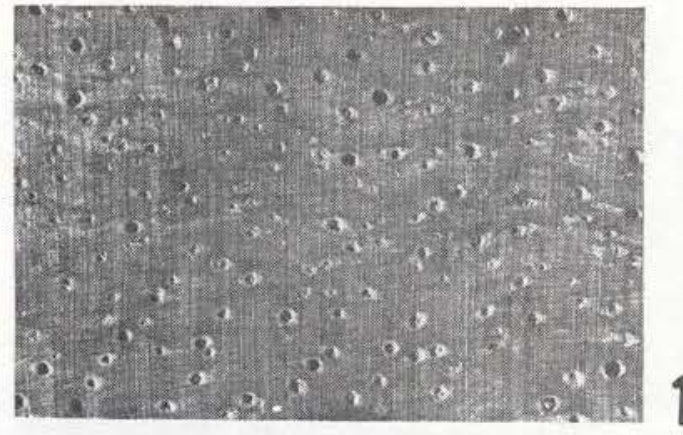

\section{$2 \mathrm{~mm}$}

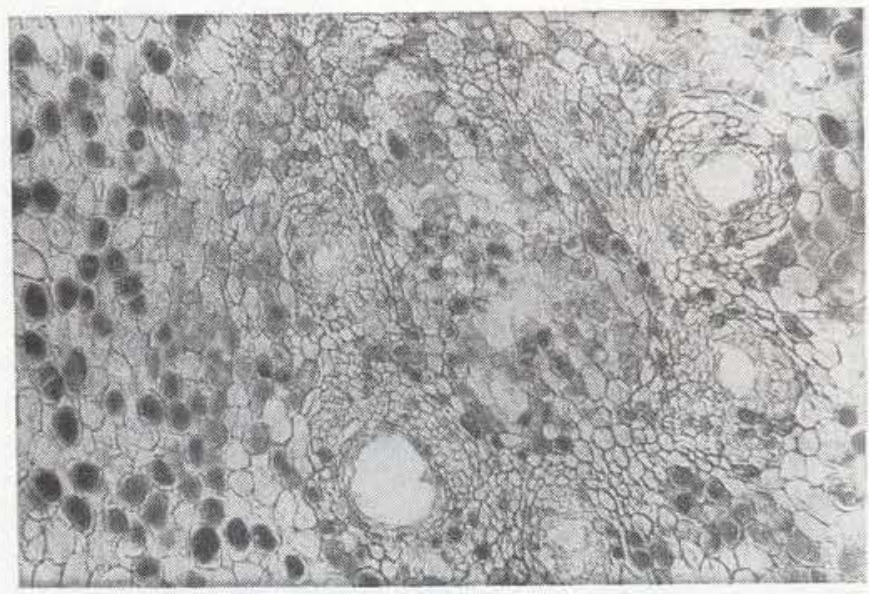

$100 \mathrm{u}$

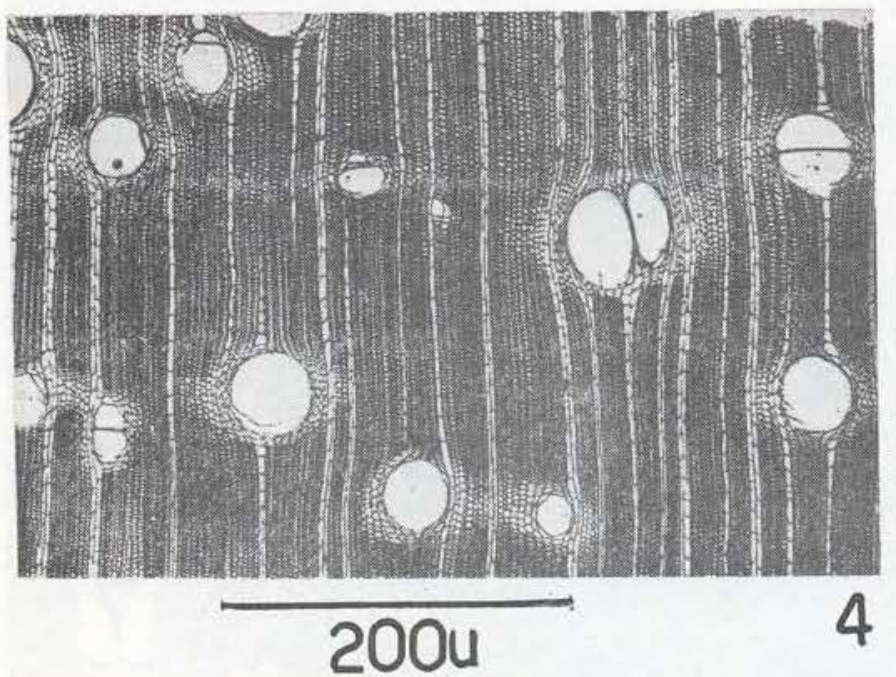

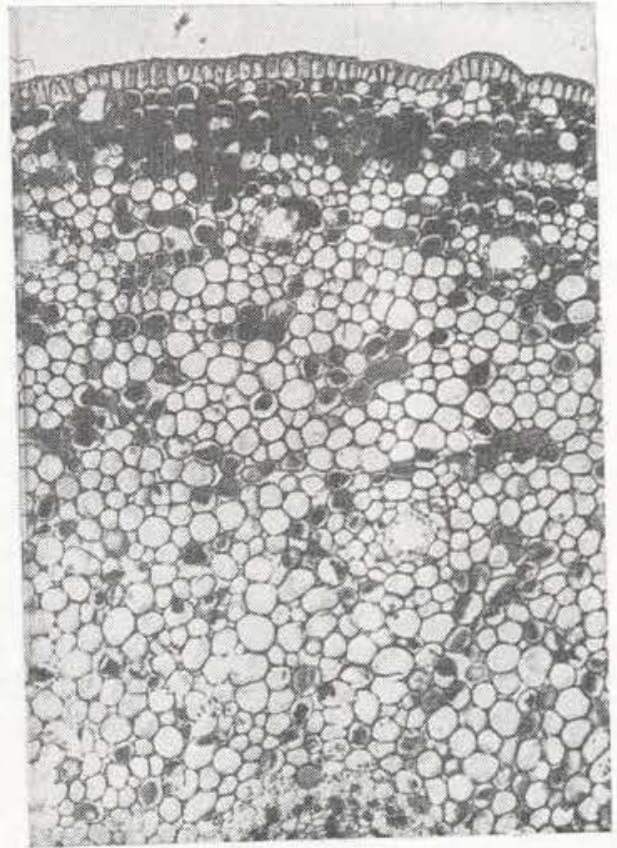

2

\section{$200 u$}

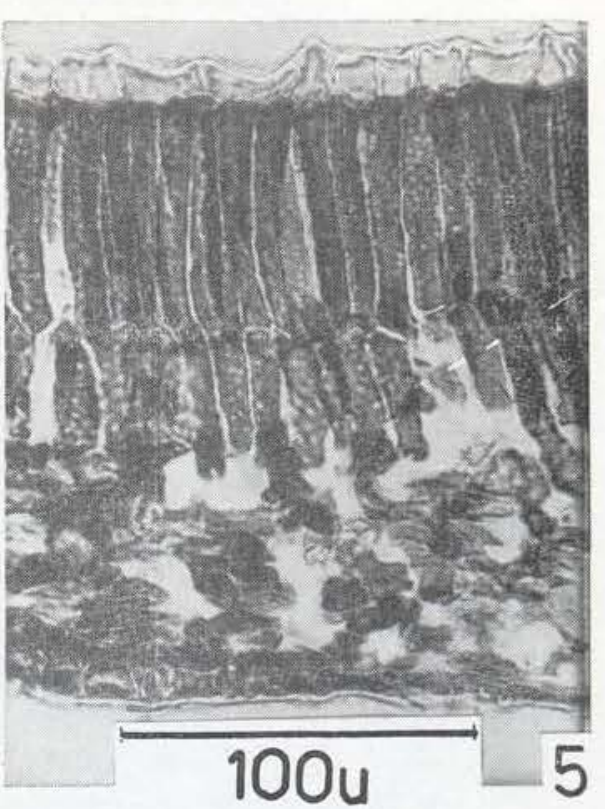

Foto 1 - Aspecto macroscópico da madeira; 2 - Estrutura primária do caule; 3 - Estrutura primária do caule mostrando as fases lisígena e esquizolisígena; 4 - Secção transversal da madeira (80X): 5 - Corte transversal da lâmina foliar (120X). 


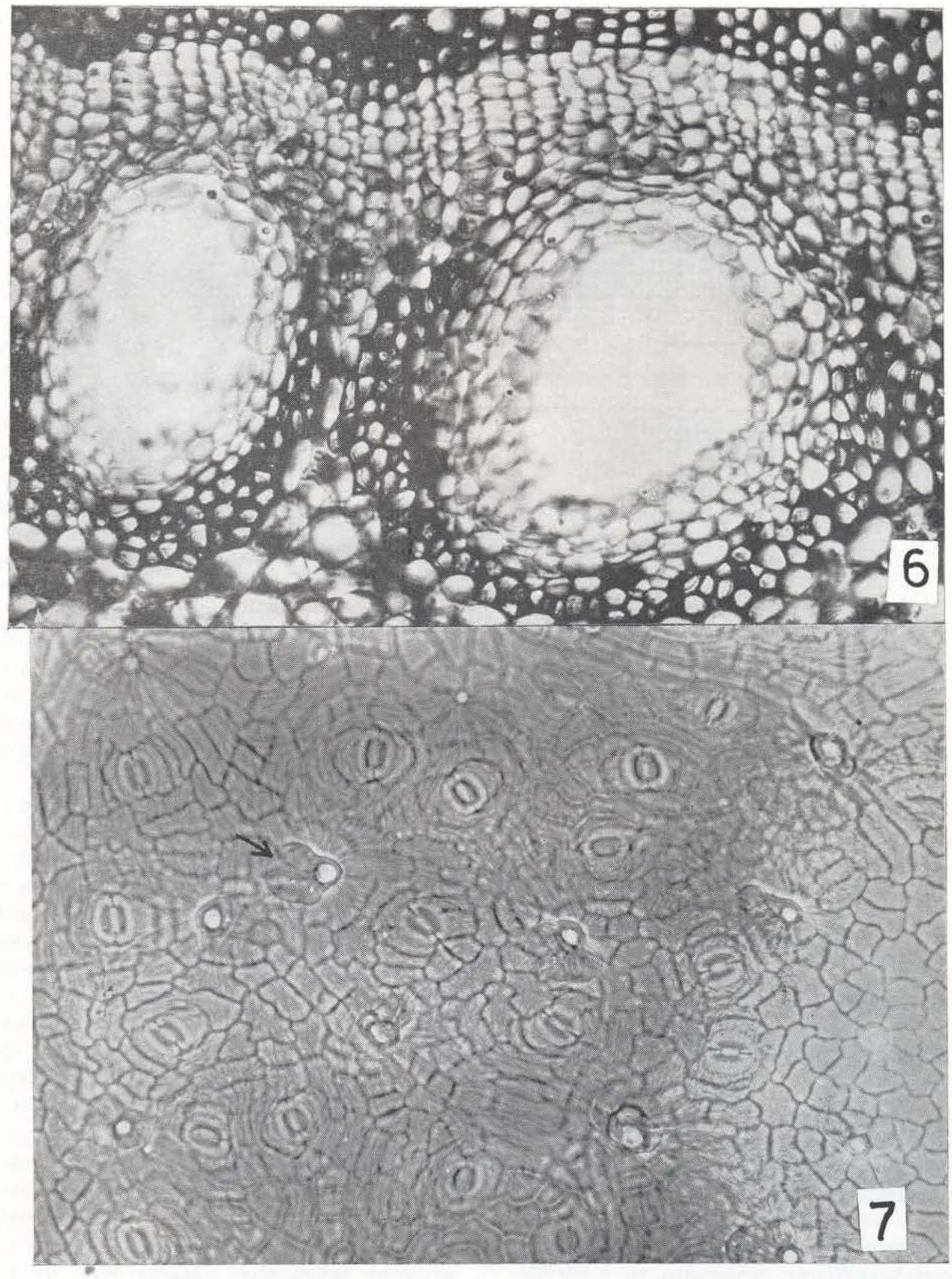

Foto 6 - Canal semi-envolvido por esclerênquima da estrutura secundária (380X); 7 - Epiderme abaxial mostrando estômatos e pêlos glandulares (130X) 
da epiderme, vistas em secção transversal são de forma retangular, com maior diâmetro periclinal; suas paredes são pouco espessas, algumas parcialmente lignificadas. $O$ tegumento interno é formado por 7-10 camadas de células de paredes finas, pectocelulósicas, ricas em polifenois. A epiderme interna, vista em corte transversal, consta de células retangulares, com maior diâmetro periclinal, ricas em polifenois. Os feixes vasculares situam-se no limite dos dois tegumentos.

Cotiledones - A protoderme é unisseriada e suas células são habitualmente retangulares, vistas em corte transversal, com maior diâmetro periclinal; freqüentemente possuem grãos de amilo muito pequenos. Sobre a protoderme há uma cutícula uniforme bastante fina.

Parênquima de reserva - $\mathrm{O}$ mesofilo cotiledonário é constituído de células amplas, de paredes finas, pectocelulósicas e cheias de grãos de amilo simples, às vezes múltiplas de dois, esféricos ou ovóides, com hilo circular ou alongado. A maior porção das substâncias de reservas é representada por grãos de amilc, existindo, igualmente, substâncias proteicas. Existem canais secretores e muitos deles se formam contíguos à região vascular (foto 12).

Eixo embrionário. $\mathrm{Na}$ semente madura, é constituído de meristema primário. O epicótilo, em corte transversal apresenta forma circular. A protoderme consta de células subcirculares e retangulares, com maior diâmetro periclinal, vistas em secção transversal; o citoplasma é bastante denso; núcleo grande; o meristema fundamental cortical e medular é constutuído de células grandes, cheias de pequenos grãos de amilo e com poucas substâncias proteicas; nele se formam canais secretores. $O$ procâmbio apresenta forma circular, visto em corte transversal; aí, se formam canais às expensas de células procambiais. Comparativamente, as estruturas do epicótilo e hipocótilo são semelhantes.

G - PSEUDO-FRUTO (hipocarpo)

A epiderme é unisseriada, com células alongadas anticlinalmente, semelhantes às paliçádicas, paredes finas, pectocelulósicas, em geral, ricas em polifenois; observamos, com pouca freqüência, células que sofreram divisões tardias, por paredes periclinais; cutícula fina. O parênquima é constituído de uma massa de tecido homogêneo, cujas células são ricas em substâncias taniferas; canais secretores estão presentes, notadamente na porção externa clesse parênquima; os grãos de amilo são escassos. Nessa massa de tecido parenquimatoso, ocorrem os feixes vasculares, sendo que, os externos obedecem um arranjo circular, enquanto que, os mais centrais são dispostos, sem orientação definida; na área onde ocorrem os feixes vascuiares, os elementos parenquimatosos são carentes de substâncias taníferas (foto 9) e suas paredes acabam por lignificar-se.

\section{H - CANAIS SECRETORES E SUA ORIGEM}

As investigações procedidas, a partir do embrião maduro, até a estrutura secundária, incluindo, portanto a estrutura primária, nos revelou os primeiros esboços de canais, precisamente na fase de diferenciação em que já se distinguem a protoderme, parênquima fundamental cortical e medular e precâmbio. Vale a pena dizer que esses canais começam a se formar a partir do meristema primário (foto 11). Acompanhando o desenvolvimento desses canais, até a sua completa formação, chegamos a conclusão de que eles são de origem esquizolisigena. Observamos que a fase esquizógena é caracterizada pelo aumento de um espaço intercelular e a fase lisigena é distinguida pela lise das paredes de várias células (fotos 3 e 11). As células atingidas pelo fenômeno de lise apresentam citoplasma denso, com pequenos vacúolos e núcleos e nucléolos bem visíveis. No embrião, principalmente, no epicótilo e hipocótilo é mais fácil observar as primeiras células (grupos de 4-6) iniciais de um canal, do que nos demais órgãos da planta, posto que são bem menores que as demais e pobres em grãos de amilo. Examinando inúmeros canais, depreendemos que os mesmos se formam, também, nas estruturas primárias e secundárias, pelo mesmo processo. Conforme ensaios histoquímicos, as substâncias existentes no interior desses canais são de natureza fenólica e resinosa. 


\section{I - MADEIRA}

Madeira leve, densidade entre 0,48 e 0,57 ; casca castanho-claro, com $1,6 \mathrm{~cm}$ de espessura; alburno esbranquiçado, observado no ato da coleta; cerne castanho-claro; textura média; Poros bem visíveis a olho nu, por causa do parênquima axial; linhas vasculares distintas, em geral retas; parênquima axial pouco distinto; raios visíveis com auxílio de lente; distribuiçâo uniforme; camadas de crescimento indistintas; canais resiníferos não foram observados (Foto 1).

Caracteres microscópicos - Poros: predominantemente solitários, as vezes múltiplos ce 2-3, distribuição difusa, de secção circular a suboval, alguns com tilos; poucos por $\mathrm{mm}^{2}$, 3 em média; grandes, $300 \mu$ de diâmetro, em média, variando entre 90 e 448 , sendo $47 \%$ entre 272 e 384; elementos vasculares com placa de perfuração simples, total, longos, $674 \mu$ de comprimento, em média, incluindo apêndices, variando entre 48 e $812 \mu$, sendo $70 \%$ entre 614 e 700; pares de pontuações intervasculares areolados, escassos, disposição alterna; contorno da pontuação aproximadamente elíptico, fenda estreita, às vezes ampla; pares de pontuações parênquima-vascular geralmente simplificados, pouco numerosos, alternos, às vezes opostos, contorno da pontuação elíptico, fenda ampla; pares de pontuações radio-vasculares semi-areolados, de contorno elíptico, às vezes subcircular, distribuição alterna, fenda ampla; raios nomegêneos, tipo I de Kribs (raios unisseriados frequentemente baixos, pouco numerosos e compostos de células idênticas às dos raios multisseriados), 1 a 2 seriados, extremamente baixos, $423 \mu$ de altura em média, variando entre 120 e $1140 \mu$, sendo $43 \%$ entre 450 e $705 \mu$, com $43 \mu$ de largura, em média, variando entre 15 e $75 \mu$, sendo $93 \%$ entre 30 e $60 \mu$, com 1 a 29 células de largura, sendo mais freqüentes entre 8 e 18, pouco numerosos, 6 por $\mathrm{mm}$, variando entre 5 e 8 , sendo mais freqüentes $(90 \%)$ os de 6 (foto 10 ); dentre as células dos raios ocorrem idioblastos contendo resina, ao lado de outras ricas em grãos de amilo. Parênquima axial: moderadamente escasso, paratraqueal vasicêntrico, sendo que alguns vasos nas faces abaxial e adaxial, o parênquima é mais escasso (foto 4). Fibras: abundantes, muito delgadas, cujo lúmem corresponde cerca de $3 / 4$ do diâmetro total da fibra, elementos fibrosos curtos, $1,2 \mathrm{~mm}$ de comprimento em média, variando entre 1 a $1,4 \mathrm{~mm}$; pontuações simples, 'bem visíveis, as vezes areoladas; fibras septadas ocorrem também.

\section{DISCUSSÃo}

Caule - Ressaltando a ausência de colênquima. Entretanto, na posição em que aquele tecido deveria se diferenciar, observamos, a existência de uma bainha polifenífera. Supomos que a ausência do colênquima deve estar relacionada com a referida bainha. No parênquima do lenho secundário ocorrem, com pouca freqüência, bolsas gomiferas, fato que não se repete no parênquima axial da madeira.

Lâmina foliar - Metcalfe \& Chalk (1957), aludem à existência de duas camadas de células no parênquima paliçádico, pelos glandulares unisseriados e multisseriados na epiderme foliar de Anacardium; Machado, (1944), salienta a ausência de pelos nas epidermes foliares de A. occidentale. Morretes (1967), menciona estômatos nas duas epidermes foliares. No entanto, nos nossos estudos da lâmina foliar de A. spruceanum, notamos a ocorrência de pelos nas duas epidermes e estômatos na epiderme abaxial, e a presença de duas camadas de células paliçádicas.

Fruto - Quanto ao pericarpo, chamamos, aqui, a atenção para o fato de que a epiderme externa representa o próprio epicarpo. A ocorrência de "pelos" nas paredes divisórias das bolsas, leva-nos a crer, que eles, têm grande influência na produção de óleo-resina. A comprovação desta hipótese poderá ser feita oportunamente, com estudo mais detalhado de frutos jovens. Paviani (1965), constatou que camada mais interna do endocarpo de Schinus é constituida de células com paredes espessas, lignificadas; já em A. spruceanum, essa camada se apresenta constituída de células de paredes finas, pectocelulósicas.

Pseudo-fruto (hipocarpo) - Foi evidenciado que sua estrutura se diferencia das estruturas do caule, da folha e do fruto, em virtude não revelar tecido típico da estrutura dos órgãos mencionados. O que ocorre é a exis- 

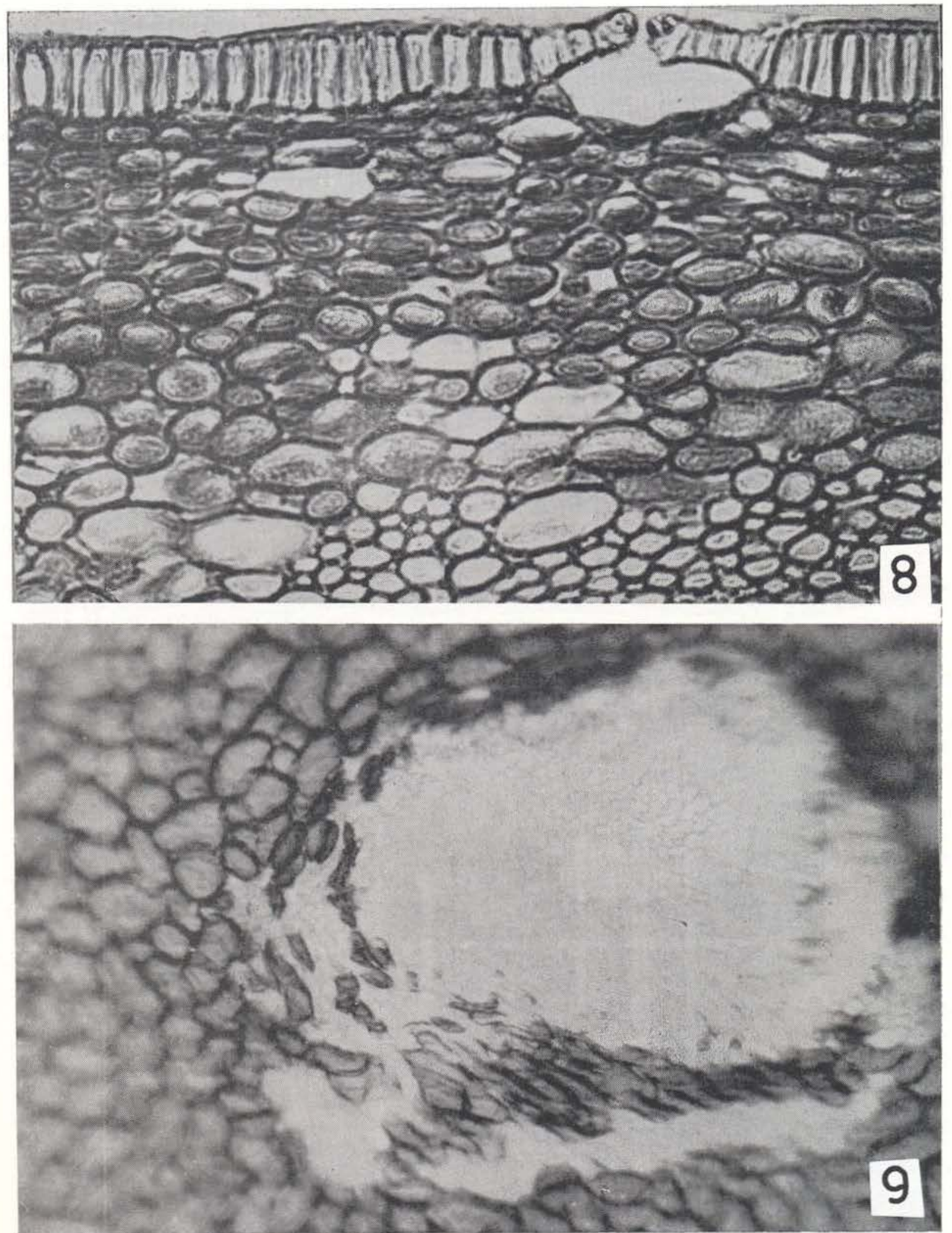

$=$

Foto 8 - Fruto : mostrando parte do mesocarpo, epi derme com estômato, e células com polifenois (380X) 9 - Pseudo fruto em corte transversal mostrn ndo um feixe vascular e células taníferas (70X) 

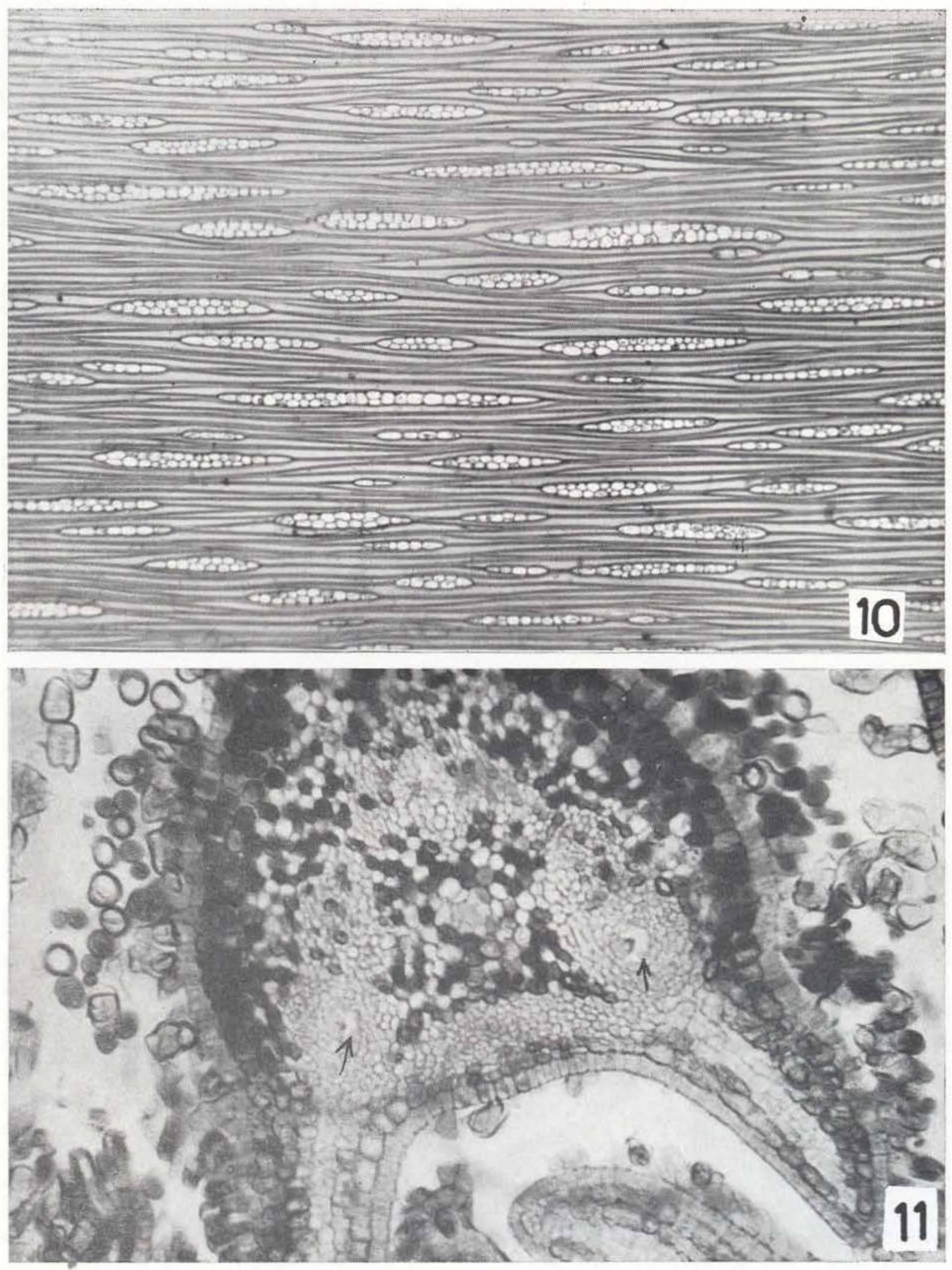

Foto 10 - Secção tangencial da madeira $(80 \mathrm{X}) ; 11$ - Brôto apical do caule mostrando primórdios foliares e os primeiros esboços de canais (130X) 
tência de epiderme com células alongadas radialmente $e$, internamente, uma massa homogênea de tecido, no qual se encontram os feixes vasculares; os mais centrais desses feixes são dispersos, enquanto que os mais externos obedecem a uma orientação no sentido circular, o que revela uma estrutura "sui generis". Quanto as células alongadas da epiderme, queremos lembrar que Machado, (1944) salienta epiderme com 1-2 camadas de células pequenas, retangulares, em $A$. occidentale.

Canais secretores - De acordo com os estudos já realizados por vários pesquisadores, sabemos que a origem dos canais secretores, pode ser de natureza esquizógena, lisigena e esquizolisigena. Engler, (1931) diz que as Anacardiaceae possuem canais esquizógenos; Harad, (1937) apesar do ponto de vista de Engler, afirma categoricamente que os frutos de Rhus sucedanea produz canais resiníferos esquizógenos e lisígenos de acordo com o seu desenvolvimento. No fruto de Simaruba amara, os canais secretores são de origem esquizolisígena (Milanez, 1946); Vemning (1948) concluiu que os canais laticíferos da folha de Schinus e fruto de Mangifera, são esquizógenos; esquizolisígenos no caule e folha de Spondias e Mangifera, e alisígenos no ovário de Mangifera. Do estudo que realizamos, em $A$. sprucearium, chegamos a evidência de que em todo material estudado, isto é, a partir do embrião até à madeira, inclusive fruto, os canais secretores observados são de origem esquizolisígena. $\mathrm{Na}$ espécie em apreço, verificamos que no eixo embrionário e no broto apical do caule, os canais referidos se formam contíguos ao procâmbio, semelhantes aos que ocorrem em Simaruba amara. Em Schinus, os canais se localizam na região do floema primário e secundário (Paviani, 1965). Entretanto, no material que estudamos, os canais se formam nos parênquimas cortical e medular, na região do floema do caule, pecíolo e nervura central. O mesmo autor menciona a ocorrência de canais no mesocarpo de Schinus mole L. Todavia, em A. spruceanum, os canais ocorrem nos cotilédones, eixo embrionário, caule, peciolo, nervura central e no pseudo-fruto; no entanto não ocorrem no pericarpo e no mesofilo. No pericarpo, foi observada a formação de bolsas.
Madeira - Record (1939) menciona tilos abundantes no cerne, raios $1-2$ seriados, raramente trisseriados, com até 40 células de altura, sendo mais freqüentes os baixos de 20 células de altura, heterogênos, em Anacardium; Metcalef \& Chalk (1957) referem parénquima confluente em Anacardium. Verificamos em A. spruceanum, poros com poucos tilos, raios lımogêneos, do tipo I de Kribs, nunca trisseriados.

\section{Agradecimentos}

Ao Dr. F. R. Milanez, Dra. Maria Artemísia, pelas sugestões valiosas e auxílio prestado no manuseio de técnicas; Prof. Byron Albuquerque, botânico do INPA, A. Neto Vieira e J. Cezário Barros, Engenheiros Florestais do INPA, pela colaboração na coleta de material.

\section{SUMMARY}

In this paper the authors studied the anatomy of the stem, the leaf, the fruit, the pseudo-fruit, and wood of the Anacardium spruceanum (Anacardiaceae of the Amazon Region).

In Anacardium spruceanum the secretory canals are schyzolysigenus. Thees have origen in the embryon in primary structure and secondary structure; occur in the cortical parenchyma, in the pith, and phloem. In the mesocarp there are cavities, with the wall covered with secretory hairs. The wood with paratracheal parenchyma is vasicentric; homogenous rays occur 1-2 seriate; fine fibres are numerous; foliar epidermis have glandular hairs.

\section{BIBLIOGRAFIA CITADA}

AguinR, F. J. DE ET ALH

1958 - Novas considerações sôbre o efeito hipoglicemiante de Anacardium occidentale L. Anais Fac. Med. Univ. Recife, 19(2): 253-367, 4 quad. 3 gráf.

Alves, J. L. H. \& Paula, J. E. DE

1970 - Anatomia de Anacardium spruceanum Bth Ex Engl. (Anacardiaceae da Amazônia). In : Res. da XXII Reun. Soc. Bras. para o Prog. da Ciên., Salvador. p : 267-268.

ENGLER A.

1931 - Die naturlichen pflanzenfamilien. Leipzig. $21 \mathrm{y}$. ilust. v. $3(5)$ : 139-140.

EsAu, K.

1959 - Anatomía vegetal. Trad. de J. P. Rosell. Barcelona, Ed. Omega. 729 p., 85 est., 20 fig. 

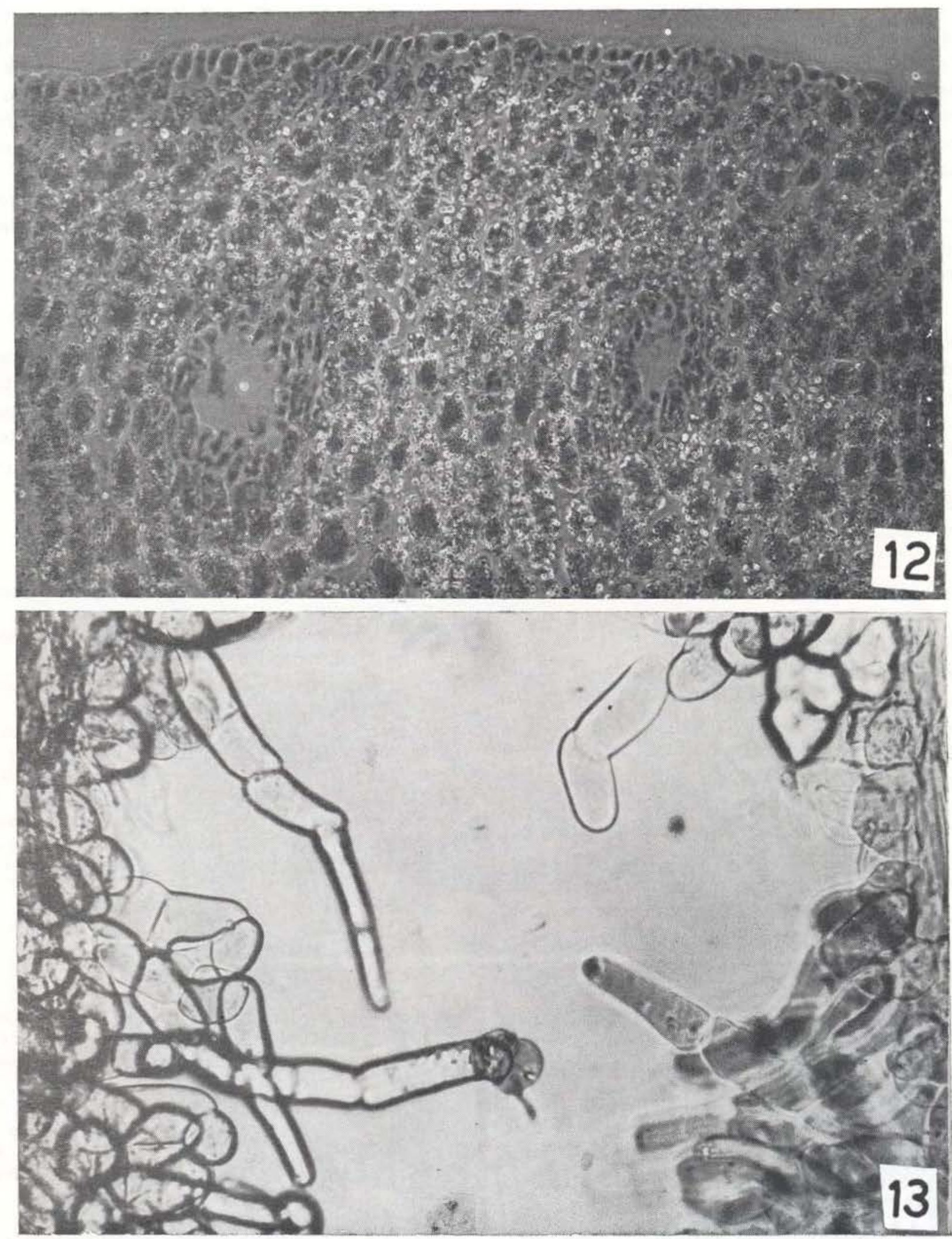

,

If Foto 12 - Corte transversal do cotilédone mostrando células com grãos de amilo e substâncias proteicas, e canais (444X); 13 - Mesocarpo mostrando bolsas e "pêlos" secretores (90X) 
Harad, M.

1937 - On distribution and construction of the resin canals in Rhus seccedanea, Bot. Mag., Tokyo. 51(611): 423-435.

JOHANSEN, A. D.

1940 - Plant microtechinique. New York, Mc-GrawHill. 523 p., il.

JENSEN, W. A.

1962 - Botanical histochemistry. London, Ed. W. H. 408 p., il.

KRIBS, D. A,

1936 - Salient lines of structural speciallization in the wood rays of dicotyledons. Bot. Gaz., Chicago 93(3): 147-151, 7 fig., lest.

Metcalfe, C. R. \& Chalk, L.

1957 - Anatomy of the dicotyledons. Oxford, Clarendon. 2 v. 1 , ilust. 724 p.

Milanez, F. R. \& Miranda Bastos, A.

1960 - Glossário dos têrmos usados em anatomia de madeira. Rio de Janeiro, Irmãos \& Cia. ed. 27 p.

MILANeZ, F, R.

1946 - Canais secretores do Marupá. Rodriguésia, Rio de Janeiro, $20: 1-40,12$ est.
MORRETES, B. L.

1967 - Contribuição ao estudo da anatomia das fôlhas de plantas do cerrado. II. Bo.l Fac. Fil. Ciên. e Letras Univ. S. Paulo, 305: Botânica, 22: 207-244, 32 fig.

O'BRIEN, T. P. ET ALII

1964 - Polychromic staining of plant cell walls by Toluidine blue. Protoplasma Cambridge, Mass. 59.: 367-373, il.

Paviani, T. I.

1965 - Contribuição ao conhecimento do género Schinus L. Anatomia de quatro espécies e uma variedade. Tese apresentada à Fac. de Farm. Univ. Santa Maria, RS. Ed Polloti. 107 p., il.

- Primeira Reunião de anatomistas de madeira. Rodriguésia, Rio de Janeiro, 1937 - 11:302-385.

RECORD, S. J.

1939 - American wood of the family Anacardiaceae Trop. Woods, Yale, 60: 11-64.

VENNING, F. D.

1948 - The Ontogeny of the laticiferous canals in: Anacardiaceae. Am. Jour. Bot., New York $35: 637-644,10$ fig. 